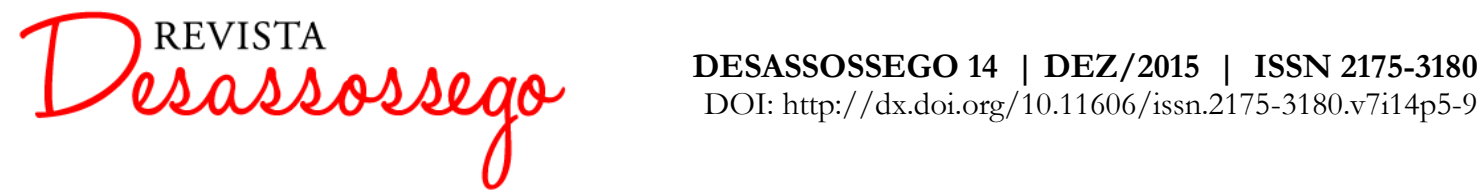

\title{
Desassossego e Orpheu
}

Lilian Jacoto ${ }^{1}$

O ano de 2015 foi um ano de celebração para a Literatura Portuguesa. Os festejos que comemoraram o centenário da Orpheu, revista fundadora do modernismo português, ultrapassaram em muito os limites da lusofonia, e um ano não foi suficiente para esgotar os sentidos da efeméride. O presente e próximo números da Desassossego são prova de que o século da publicação de Orphen não acabou, ele continua pela (re)ativação de um debate que prossegue pelas universidades, pelas editoras e pelos leitores da boa poesia. Não à toa os eventos que pelo mundo se multiplicam teimam em repetir o presságio de Fernando Pessoa, adiando sua conclusão: "Orpheu acabou. Orpheu continua".

O Dossiê, que aqui apresentamos, colhe, em boa parte, os frutos do Congresso Internacional Luso-Brasileiro 100Orpheu, ocorrido em maio de 2015 na Universidade de São Paulo (a que esta revista - cujo nome se inspira na aventura órphica - está originalmente ligada), e cuja realização se deu em conjunto com pesquisadores da Universidade de Lisboa.

Agradecemos o envio de contribuições de conferencistas, oradores e comunicadores (além dos que, não tendo participado do evento, vieram aqui integrar o debate), enfim a todos os que submeteram seus textos à Desassossego que é, hoje, um canal expressivo dedicado à divulgação da pesquisa em Literatura Portuguesa, com a colaboração de professores e discentes de pós-graduação. É a esse público que o centenário de Orpheu comprova aqui a sua importância. Fato é que a comemoração do centenário resultou numa plêiade de artigos que ocuparão certamente não só este número, mas também o próximo. De modo que se optou por organizar tematicamente os dossiês dos números 14 e 15, ambos dedicados ao Modernismo. Em posse de uma maioria de textos a falar da obra de Fernando Pessoa, os editores decidiram dedicar o presente dossiê a uma visão geral sobre os artistas que colaboraram na Revista Orpheu; e reservaram o próximo número à predominância da figura de Pessoa que, com Mário de SáCarneiro, dividiu o sonho de criar uma revista que mudasse a história de seu país.

Richard Zenith, no texto de apresentação ao catálogo da exposição comemorativa da Biblioteca Nacional de Portugal - Os caminhos de Orpheu -, avalia o êxito desse propósito: "No

\footnotetext{
${ }^{1}$ Professora de Literatura Portuguesa da Universidade de São Paulo (USP).
} 


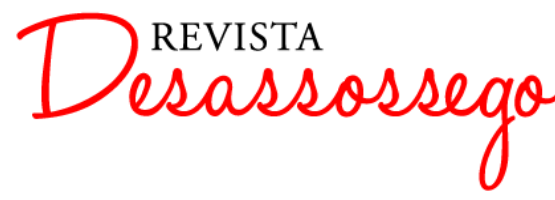

espaço de quatro meses, em 1915, reviraram a literatura portuguesa, que nunca mais seria a mesma. A relativa exiguidade do espaço cultural português e o seu maior conservadorismo foram decisivos para que Orpheu causasse tamanha perturbação, semelhante a um novo terramoto que, desta vez, sacudiu a própria mentalidade, levando à queda de valores estéticos consagrados, primeiro em Lisboa, e depois no resto do país”. (ZENITH et alia (org.), Babel, 2015).

No atual conjunto de textos, o leitor encontrará uma abordagem sinfônica (melhor seria dizer dodecafônica) que faz entender a Revista Orpheu na sua proposta estética intrínseca, na sua estrutura, na sua diversidade, no lugar em que ela movimenta e desloca a tradição; também sua relação com o mundo circundante e seu potencial de continuidade em direção ao contemporâneo.

Passado um século de reflexão, o conjunto inacabado de Orpheu ostenta as mais diversas interpretações, a começar pela própria ausência de um manifesto ou programa objetivo que a Revista pretendia cumprir. Jerónimo Pizarro examina essa suposta lacuna, ao lado de outras contradições que dotam o modernismo português de curiosas singularidades. Com um introito que, em vez de combativo, convida o leitor ao exílio, Orphen encontra uma forma muito própria de épater o seu século e nele existir. Como editor e exegeta, Pizarro examina a matéria da Revista à luz de documentos de conhecimento ainda restrito, iluminando novas hipóteses sobre o projeto modernista.

Em princípio é necessário pontuar que as leituras atuais desse projeto, em geral, não ignoram o olhar de Jano que a Revista lança ao tempo, sem pudores de reconhecer a tradição que ela retém para então avançar nas experimentações de linguagens mais ousadas. O olhar que lança em direção a um passado então recente e não esgotado em sua potencialidade criadora é tema do artigo de Fernando Gebra. Nele, o pesquisador faz decantar, da poética moderna de Orpheu, uma linhagem "crepuscular" (simbolista e decadentista) que Alfredo Pedro Guisado (ainda pouco iluminado pela crítica) representa. Ao lado de um Sá-Carneiro afeito ao lirismo saudosista, essa linhagem encontra ecos da poética de António Nobre como substrato, o que confere ao grito modernista vibrações melancólicas ainda eivadas de uma angústia metafísica que a modernidade só faria agudizar.

Mas como era de se esperar, predominam as abordagens do novo, do agônico e o belicismo moderno que Orphen bem assimila em vozes pontuais. Nas palavras que Orlando 


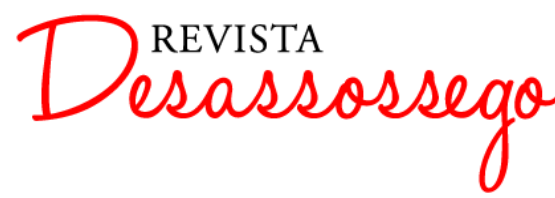

Amorim recupera de Pedro Eiras, o nietzscheanamente leonino Almada Negreiros vem protagonizar o espírito da vanguarda que Orpheu projeta para muito além do seu tempo. $\mathrm{Na}$ análise que faz da "Cena do Ódio", poema anunciado para a Orphen 3 que ficou inédita, e que teria sua versão definitiva só em 1958, Amorim dá a dimensão polifônica e responsiva que o modernismo português teve com o seu tempo, sublinhando a paronomásia e paralelismo estrutural que o ódio estabelece com a ode (relação que Mário de Andrade também consumara em sua "Ode ao Burguês”, tão famosa entre os libelos do movimento modernista brasileiro).

A mesma "Cena do Ódio" e outras produções odiosas de Almada ganham ainda a análise algébrica de Nicolás Barbosa López que, numa visada aos desvios de uma gramática própria, apoia-se na álgebra impossivel-factivel do poliartista, numa matemática estranha a embasar uma linguagem a um tempo demolidora e criativa. Nicolás centra sua atenção na "capacidade [de Almada] de criar novos códigos e destruir os anteriores”, movida pelo ódio e pela barbárie que sempre estiveram presentes sob o verniz da civilização.

Reivindicar para si uma pátria que o mereça é a atitude que o artigo de Dionísio Vila Maior vem sublinhar nesse ethos singular de Almada Negreiros. Afinal o estudioso de Fernando Pessoa vem mostrar que também Almada, sujeito modernista igualmente fraturado, projetara toda uma obra como antídoto da decadência em que Portugal, mais que a Europa, estava metido. Em seu artigo, Vila Maior aponta a perfeita assimilação do vitalismo beligerante do artista com o espírito belicista das vanguardas - "expressão artística mais legítima do século", a extrair da guerra todo o seu potencial simbólico e revisionista da civilização.

Ainda Almada, ao lado de Santa-Rita Pintor, constitui o foco de mais um brilhante artigo, escrito pelo estudioso galego Carlos Paulo Martinez Pereiro. Fazendo coro com a exaltação dos demais comentadores do artista, Pereiro esclarece as influências oblíquas que o futurismo legou ao Orpheu ou, em suas palavras, revisita "a devoração lusa das tendências futuristas". Se por um lado temos Santa-Rita como artista sem obra (uma possibilidade que só o espírito vanguardista do século XX pode acolher), Almada Negreiros é festejado como artista-síntese das tendências e propósitos mais caros de Orpheu, e nessa síntese o estudioso aponta a bagagem futurista no borramento que sua obra realiza sobre limites, campos epistemológicos, gêneros e linguagens, com destaque para o diálogo interartes que o poliartista, mais que todos, soube naturalmente cumprir. 


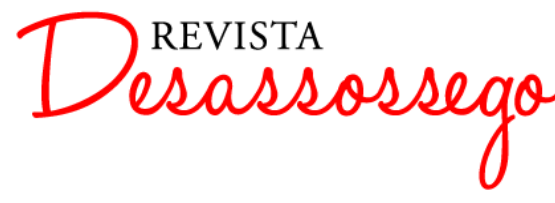

Mas se a questão é apontar o espírito que, dentre os artistas de Orpheu, melhor representou a intentona vanguardista em seu maior alcance, leia-se o artigo de Piero Ceccucci a respeito da genialidade e loucura de Ângelo de Lima. Para além da esquizofrenia que se fez alvo dos piores ataques ao grupo, famigerando-o como bando de loucos, Ceccucci nos mostra o amplo espectro que teve a contribuição do artista, desde a prática de uma poética simbolista preparatória do modernismo, até a antecipação de procedimentos das vanguardas da segunda metade do século XX, através de uma exploração sensorial do significante e de um anagramatismo que só as gerações da PO-EX, da Poesia Visual e da Poesia Sonora lograram alcançar.

E incrementando o diálogo interartes, vem-nos a preciosa contribuição de Rosa Maria Martelo a discutir a ambígua relação que Fernando Pessoa, como teórico do sensacionismo, estabeleceu entre a literatura e as outras artes. Através de uma leitura suspeitosa e modalizadora de textos de reflexão estética em que Pessoa abusa de um "radicalismo pouco demonstrativo", Rosa Martelo analisa o percurso retórico que o poeta adota para formular uma estética eminentemente verbal e holística, levando à radicalidade a hierarquização das artes que o Romantismo havia inaugurado. Rosa nos fala de um lugar que conhece a fundo a poesia contemporânea, donde pode aquilatar a herança pessoana sobre grandes nomes do presente. Afinal a soberania que o poeta confere à literatura, desmerecendo as demais linguagens artísticas, acaba por fazer reconhecer a importância de todas elas para a grande síntese que o sensacionismo planeou para si e legou à sua posteridade.

Ainda a produção poética do Pessoa ortônimo comparece em dois artigos, por dois ângulos de leitura bastante diversos. Por um lado, e como resultado de uma trajetória crítica que se iniciou na década de setenta, Maria Helena Garcez avança com a proposta de uma revisão crítica sobre o poeta do Cancioneiro, a partir das leituras que as novas edições permitem de poemas até há pouco inéditos. Garcez ilumina facetas inéditas ou despercebidas de um Pessoa Ele Mesmo, desafiando a ideia hoje preponderante na crítica de que toda a obra do poeta tenha sido escrita sob o ethos do fingimento. Esse novo/outro revisitado Pessoa desenha uma linha que renega o "forte intelectualismo da modernidade" que perdura para além do seu século, para se entregar à rememoração de um passado biográfico e de uma experiência do sagrado só porventura vivido no ambiente familiar da infância. 
Por outro lado, Maria Heloísa Martins Dias explora, numa visada sensível (à flor da pele e dos ouvidos) o processo órfico que constitui a leitura da obra pessoana. Num contraponto que só enriquece o debate, a ensaísta desenvolve a ideia da "obra-em-processo", sublinhando o aspecto lúdico e de obra aberta que é esse infinito conjunto de "peças móveis que nunca acabam de formar os mais curiosos painéis ou paisagens", um “exercício de dominó poético", "uma arte que faz da desrazão o verdadeiro impulso a movimentá-la”. O aspecto lúdico realiza o projeto órfico como exílio do mundo, refúgio poético (criativo) para a consciência fraturada do sujeito moderno, esse que existe em eterna dissonância com a paisagem a que chamam real.

Enfim, se os poetas de Orpheu quiseram refundar a civilização sobre bases radicalmente diferentes que as da cultura do esclarecimento; se ousaram inventar uma coterie de homens cultos, artistas superiores, mentes criativas e capazes de refundar também uma pátria que os merecesse, estão aqui alguns caminhos que permitem compreender tamanho projeto. Depois de Orpheu, o mundo mudou, está mudando. Penso, entretanto, que ainda carecemos de grandes indisciplinadores que nos salvem de uma ordem que, a despeito da aparente liberdade que hoje gozamos, nós não escolhemos. 